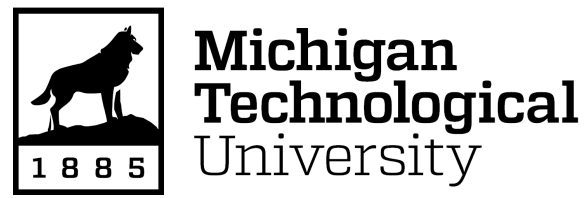

Michigan Technological University Digital Commons @ Michigan Tech

Dissertations, Master's Theses and Master's Reports

2021

\title{
UTILIZATION OF PAENIBACILLUS POLYMYXA IN THE RECOVERY OF LITHIUM BEARING MINERALS
}

Diana Bullen

Michigan Technological University, dbullen@mtu.edu

Copyright 2021 Diana Bullen

\section{Recommended Citation}

Bullen, Diana, "UTILIZATION OF PAENIBACILLUS POLYMYXA IN THE RECOVERY OF LITHIUM BEARING MINERALS", Open Access Master's Report, Michigan Technological University, 2021.

https://doi.org/10.37099/mtu.dc.etdr/1307

Follow this and additional works at: https://digitalcommons.mtu.edu/etdr

Part of the Environmental Health Commons, Environmental Sciences Commons, Geology Commons, and the Microbiology Commons 
UTILIZATION OF PAENIBACILLUS POLYMYXA IN THE RECOVERY OF LITHIUM BEARING MINERALS

By

Diana Bullen

A REPORT

Submitted in partial fulfillment of the requirements for the degree of MASTER OF SCIENCE

in Geology

\section{MICHIGAN TECHNOLOGICAL UNIVERSITY}

2021

(C)2021 Diana Bullen 
This report has been approved in partial fulfillment of the requirements for the Degree of MASTER OF SCIENCE in Geology.

Department of Geological Mining and Engineering Sciences

\author{
Report Advisor: $\quad$ Nathan Manser
}

Committee Member: John Gierke

Committee Member: Luke Bowman

Department Chair: Aleksey Smirnov 


\section{Acknowledgements}

This work is supported by the Michigan Space Grant Consortium under grant \# R86304 and the Department of Geological and Mining Engineering and Sciences at Michigan Technological University. Thank you to my family and friends for their support during my entire educational career. 


\section{Abstract}

In the global transition to green energy in the transportation and power production sectors, lithium has emerged as a viable solution, and crucial component, for the effective storage of renewable resources. To avoid further degradation of the land due to mining for virgin material, methods focused on recovering lithium must be developed. This research project seeks to explore a new way to recover lithium by using the bacterium Paenibacillus polymyxa. The bacteria were grown and then applied to the lithium bearing mineral spodumene. Settling velocity profiles were constructed for different treatments of spodumene. It was found that the spodumene exposed to $P$. polymyxa had a slower settling velocity profile compared to unexposed spodumene. This result implies that the bacterium successfully adhered to spodumene and easier recovery of the mineral from waste material is possible. 


\section{Introduction}

Over the past few decades, there has been a global shift away from reliance on fossil fuels. With this transition, a new dependency on green energy from renewable resources such as solar, wind, and water has emerged. There are numerous reasons for this switch to renewable energy including the reduction of greenhouse gases and air pollutants. This change is apparent in both the transportation and power production sectors, specifically with the electrification of vehicles at almost every major automotive company (Kavanagh et al., 2018). However, this transition towards green energy has created a new demand for the effective and efficient energy storage generated from renewable resources (Peters and Weil, 2016). One solution to this problem came in the form of the common lithium ion rechargeable battery. Lithium-ion batteries can effectively store energy produced from renewable sources (Rosendahl and Rubiano, 2019). In addition, lithium ion batteries were chosen as a viable option due to their ability to provide high energy density, a low sensitivity to temperature change, and the ability to hold a charge for both portable and stationary devices (Wagner, 2011). With the everincreasing demand for electric vehicles and storage units, the demand for lithium is steadily increasing (Graham et al., 2021). While lithium a relatively common metal element, it is still difficult to find and excavate in quantities large enough to justify the economic costs for retrieval and processing (Kavanagh et al., 2018).

The economic feasibility for recovering lithium generally depends on the size of the identified deposit, lithium content, and costs involved with both the extraction and processing of the material (Peiró et al., 2013). The major lithium sources include clay formations, brines, and hard-rock deposits (Figure 1). Hectorite is the clay that has been found to contain lithium. Hectorite is a magnesium lithium smectite that are chemically weathered volcanic rocks. The most common area that hectorite is found in the United States is on the Nevada/Oregon border where the McDermitt caldera is located (Evans, 1978). The method of excavation is drilling and later processing with selective chlorination. Hectorite is not a major source of lithium used in production (Peiró et al., 2013).

There are three types of brines where lithium is found: continental, geothermal, and oilfield. Six distinct environmental conditions result in brine formation. The characteristics include an arid climate, the presence of a salt lake or crust in a closed basin, geothermal activity, tectonic subsidence, lithium sources, and sufficient time for the brine to concentrate (Munk et al., 2016). Continental brines - also referred to as salars - are developed when leaching occurs in volcanic rocks. This type of formation is more common in areas where there are large volumes of fresh water and low evaporation rates (Evans, 1978). These brines are most commonly found in the salt lakes of South America (Peiró et al., 2013). The high concentration of lithium in continental brines is attributed to effective geochemical conservation in both magmatic and low-temperature solutions (Munk et al., 2016). Geothermal brines contain lithium due to the effectiveness of hot water leaching minerals from rocks. To recover lithium from the geothermal sources then physiochemical methods, such as ion exchange, are advantageous. Volcanically active countries, such as Iceland, New Zealand, and Japan, have high concentrations of geothermal brines (Kavanagh et al., 2018). The most well-known location of geothermal brines in the United States is in the Salton Sea located in Southern 
California (Evans, 1978). Oilfield brines, also known as mineral-rich brines, are produced as a result of the oil extraction process and are considered to be a waste product (Kavanagh et al., 2018). Oilfield brines considered to be potentially beneficial toward lithium production in the United States are in the oilfields of North Dakota, Wyoming, Oklahoma, Utah, and Arkansas (Evans, 1978). Canada, Germany, and Israel all have potential sources. The methods needed for extraction of these lithium sources are incredibly expensive, and currently, the costs of production do not justify continued extraction (Kavanagh et al., 2018).

The hard-rock formations in which lithium are most commonly found are called pegmatites. A pegmatite is a coarse-grained igneous rock that forms due to the crystallization of post magmatic fluids and subsequently occurs near large magmatic intrusions. The most common lithium-bearing minerals present in pegmatite are called spodumene and lepidolite (Evans, 1978). Pegmatites are fairly common but lithiumbearing pegmatites only make up $1 \%$ of the world's pegmatite resources. The main producers for the lithium supply from pegmatites are found in Australia, Canada, and Zimbabwe (Kavanagh et al., 2018). Since this is a hard-rock source, destructive mining methods must be used to extract the desired material from the bedrock. The processing of pegmatites is expensive due to the use of both roasting and leaching methods. Since the concentration of lithium recovered is higher compared to clay or brine sources, the cost is justified (Meshram et al., 2014). The recovery rates from extraction range from $60-70 \%$ but present challenges during the removal phase due to the hardness of the gangue. Pegmatite veins which contain lithium-bearing minerals are found deep underground meaning a large-scale excavation is required (Grosjean et al., 2012). This leads to an alteration of the natural landscape potentially resulting in serious damage to the surrounding environment and ecosystem health (Tost et al., 2018). The thermochemical processing treatment uses a multitude of energy-consuming furnaces, polluting fuels, and concentrated chemicals (Grosjean et al., 2012).

Despite the many sources of lithium listed above, there have been conflicting reports on the abundance of lithium and if a shortage of this valuable resource is imminent. On one hand, there has been an increased concern about lithium's availability due to the exponentially increasing demand for green energy storage. It is thought that the anticipated demand for electric vehicle batteries will soon increase past the threshold for what can be sustained by mining alone and that new methods of recycling lithium must be created (Sonoc and Jeswiet, 2014). Both extractable lithium deposits and the quality of lithium extracted need to be appraised when considering lithium availability otherwise the true availability will be skewed (Narins, 2017). On the other hand, lithium is viewed as an abundant resource. One study that looked at the five main countries with lithium supplies concluded that lithium is abundant and can be mined at a reasonable cost (Graham et al., 2021). Another study determined that if recycling was used in conjunction with mining there would be less concern for a long-term shortage based on current lithium demands (Bowell, et al., 2020). These opinions do not take into account the predicted increase in demand with the surge of electronic devices and vehicles (Meshram et al., 2014). Nor do they account for the fact that only about $1 \%$ of lithium is currently recycled (Kavanagh, et al., 2018). Research suggesting lithium's abundance has not 
considered the environmental costs if mining and other forms of lithium recovery and processing continue at the necessary rate to keep up with increasing demands.

The automotive market will continue to experience an increasing demand for electric vehicles as the progression away from fossil fuels continues. To keep up with the demand from consumers, more mines will open while existing mines are expanded. This will lead to unsustainable excavations of pegmatites to retrieve the lithium resources (Grosjean et al., 2012). The grade of the lithium will decrease as the resource becomes depleted. The grade of the deposit has a direct effect on the design and sustainability of both the mine and the processing facilities. Local communities' health will be negatively impacted. Water quality, local air quality, and the health of the surrounding environment will also face negative impacts (Ambrose and Kendall, 2019). Mining has drastically increased the occurrence of toxic elements in soil, water, air, and food products (Nieder et al., 2014). This pollution is linked to the discharge of mine or processing waste, tailings dam failures, and the remobilization of the elements from contaminated floodplains (Nieder et al., 2014). Other known impacts include topographic degradation, native fauna removal, and removal of agricultural soils (Okunlola and Ocan, 2002).

Due to the numerous negative environmental impacts associated with mining, recycling lithium would yield a more sustainable method of harvest. This is why we set out to test a new strategy for treating the lithium-bearing mineral spodumene, which is commonly found in the hard rock source (pegmatite), to recover and reuse. A Biologically Enhanced Recovery System (BERS) was developed. Using the BERS potentially has many environmental and economic benefits while avoiding the negative consequences of mining for virgin material. This process utilizes bio beneficiation and the bacterium Paenibacillus polymyxa to alter the surface chemistry of spodumene in a controlled setting. P. polymyxa is found naturally in soil, plant tissue, hot springs, and marine sediments (Lal and Tavacchioni, 2009). Studies show that $P$. polymyxa generates polysaccharides, which results in a change of surface chemistry and settling characteristics, to the point of hydrophobicity, on the mineral it is exposed to (Deo and Natarajan, 1998). Previous studies have utilized $P$. polymyxa to determine whether characteristics of specific minerals were changed after exposure. One study exposed pyrite and chalcopyrite to a pure strain of $P$. polymyxa to determine if any surficial chemical changes occurred. The change was evaluated with infrared spectroscopy. It was found that pyrite flotation was affected (Sharma and Rao, 1999). Another study successfully utilized $P$. polymyxa to selectively separate pyrite and galena, with the objective of successful recovery of galena (Patra and Natarajan, 2006). A study that exposed $P$. polymyxa to hematite, corundum, quartz, and kaolinite observed changes in the surface chemistry on all of the minerals. After biotreatment was completed quartz and kaolinite became more hydrophobic while the hematite and corundum displayed hydrophilic behavior (Deo and Natarajan, 1998).

Based on these observations and past research, we hypothesize that spodumene will display hydrophobic characteristics when exposed to $P$. polymyxa and change the settling velocity profile. While this hypothesis is theoretically possible, it requires experimental testing for measuring the feasibility. Early stages of experimentation include bench testing to prove that the conceptual aspect holds merit. The driving 
question of this research is whether the settling velocity of unaltered spodumene is greater than the settling velocity of spodumene that was exposed to $P$. polymyxa.

\section{Methods}

\subsection{Experiment Design}

2.1.1 Bacterial Strain and Reactor Operating Conditions

A pure strain of $P$. polymyxa 842 was used in all the studies. A $10 \% \mathrm{v} / \mathrm{v}$ of an active inoculum was added to Bromfield medium (Phalguni et al., 1996) and incubated at $30^{\circ} \mathrm{C}$ in a 2000-milliliter jacketed-glass beaker being stirred at $150 \mathrm{rpm}$. The bacterial growth pattern was studied by measuring volatile solids concentrations over time using a standard method. A concentration of 10 cells $/ \mathrm{ml}$ was estimated. The $\mathrm{pH}$ changes during bacterial growth and solution temperature were continuously monitored using lab view hardware and software made by Vernier. The bacteria were maintained by adding 120 $\mathrm{mg} / \mathrm{L}$ of biological grade sucrose, $8 \mathrm{~g} / \mathrm{L}$ of growth medium for micro and macro nutrients; and 5\% (v/v) of 10x phosphate buffer to avoid system collapse.

\subsubsection{Mineral Sample Preparation}

The mineral chosen to conduct the preliminary tests was spodumene. Spodumene is a pyroxene mineral that is commonly present in pegmatites, a frequently mined rock, and is a common source of lithium. After obtaining pulverized spodumene from an outside vendor, samples were classified using 50-, 100-, and 200- mesh sizing to ensure that the size distribution of particle diameter was consistent with each given sample.

\subsubsection{Mineral/Bacteria Interaction}

Prepared mineral samples were mixed with $200 \mathrm{ml}$ of activated biomass from step 2.1.1 and mixed on a rotary shaker at $150 \mathrm{rpm}$ for 24 and 48 hours. The mineral was then used for settling velocity experiments in either a wet or dried form. Dried mineral samples were desiccated at $105^{\circ} \mathrm{C}$ for 24 hours.

\subsection{Analytical Methods}

\subsubsection{Settling Velocity}

To understand the effect $P$. polymyxa had on spodumene settling, four different treatments were done. Settling velocities were calculated for each treatment and each particle size due to particle sizes' influence on settling velocity. The four treatments of spodumene were; spodumene that had not been exposed to $P$. polymyxa, spodumene that had been exposed to $P$. polymyxa for 24 hours, spodumene that had been exposed to $P$. polymyxa for 24 hours and then dried for 24 hours, and spodumene that had been exposed to $P$. polymyxa for 24 hours and then dried 48 hours. Each sample was dispersed into a $1000-\mathrm{mL}$ beaker filled with room temperature water. As the sample was dispersed, an iPhone was used to record the particles descent. Settling velocities were calculated from the measured distances and times. For each particle size, 10 different particles were tracked and used to quantify the velocity. Additional calculations were completed using Stoke's Law to compare the expected settling velocities for each mesh size to the values of unaltered spodumene extrapolated from the lab data. 


\subsection{Statistical Methods}

\subsubsection{Descriptive Statistics}

To simplify the data gathered after determining the settling velocity of each particle size fraction, the mean value was determined for each category of treatment. The standard deviation of each sieve size was calculated as well.

\subsubsection{Inferential Statistics}

A $t$-test was used to compare the settling velocities found for the spodumene particles exposed to $P$. polymyxa that was dried for 24 hours and the settling velocity of unaltered spodumene. The $t$-test helped determine if there was statistical significance between the values. That is if the difference between the settling velocity of spodumene exposed to $P$. polymyxa was large enough to result in an identifiable and statistically relevant outcome compared to unaltered spodumene.

\section{Results}

\subsection{Analytical Methods}

\subsubsection{Settling Velocity}

The spodumene particles, regardless of exposure to P. polymyxa, experienced a decrease in settling velocity as the particle size decreased (Figure 2). Of all the treatments done, the spodumene that was exposed to the organism for 24 hours and was still saturated had the highest settling velocities with an average across all three sieve sizes of 21.81

$\mathrm{mm} / \mathrm{sec}$. The spodumene that was exposed to $P$. polymyxa for 24 hours and subsequently dried for 48 hours had the next fastest settling velocity with an average of $17.24 \mathrm{~mm} / \mathrm{sec}$. The unaltered spodumene had an average velocity of $15.18 \mathrm{~mm} / \mathrm{sec}$. The spodumene that was exposed to P. polymyxa and then dried for 24 hours was found to have the slowest settling velocity with an average of $14.43 \mathrm{~mm} / \mathrm{sec}$ (Table 1). The values found using Stoke's Law were $8.7 \mathrm{~mm} / \mathrm{sec}$ for the $50 \mathrm{mesh}, 2.10 \mathrm{~mm} / \mathrm{sec}$ for the $100 \mathrm{mesh}$, and 0.5 $\mathrm{mm} / \mathrm{sec}$ for the 200 mesh.

\subsection{Statistical Methods}

\subsubsection{Inferential Statistics}

The $t$-test determined that the settling velocity profiles of the unaltered spodumene and the spodumene that was exposed to $P$. polymyxa for 24 hours and dried for 24 hours had statistical significance. The values found were 0.111 for the 50 -mesh particle size, 0.114 for the 100-mesh particle size, and 0.566 for the 200 -mesh particle size.

\section{Discussion}

As the global transition away from fossil fuels and towards renewable resources occurred a demand for effective green energy storage emerged (Peters and Weil, 2016). The solution to this problem was the common lithium-ion battery due to its high energy density (Wagner, 2011). The green energy revolution has turned lithium into one of the world's most crucial raw materials. The major lithium sources of clays, brines, and hard rock produce large quantities of usable lithium. There are concerns regarding a lithium shortage occurring due to increased demand from the transportation and power 
production sectors (Kavanagh et al., 2018). Developing strategies to recycle lithium must be pursued not only to fill the gap that these sources cannot sustain but also to prevent the negative environmental impacts seen from lithium mines (Sonoc and Jeswiet, 2014). There have been detrimental effects from mining seen in both ecosystem and human health. Lithium mines have been the causation of toxic elements present in the soil, air, water, and food products (Nieder et al., 2014). There is promising research in the use of bio beneficiation - and the bacterium Paenibacillus polymyxa - to recover minerals. $P$. polymyxa has been shown to alter the surface chemistry of minerals by generating polysaccharides which are absorbed onto the surface of the targeted mineral. The polysaccharides create hydrophobic tendencies separating the mineral from other materials present (Deo and Natarajan, 1998).

The purpose of this report was to determine if the bacterium Paenibacillus polymyxa would have any effect on the settling characteristics of the lithium bearing mineral spodumene. The settling velocities differed for the spodumene particles that were exposed to $P$. polymyxa and dried compared to the particles that were not exposed. The ttest results indicate that treatment to the spodumene particle has statistical significance on the settling velocity profile. Originally, all settling velocities were to be calculated with spodumene that had been exposed to the organism with no further processing. However, as seen from the data collected above, the spodumene particles that were only exposed to $P$. polymyxa and not dried had a very large increase in settling velocity compared to the unaltered spodumene. We think that this is because the particles were fully saturated causing the individual particles to clump together and be transported faster than expected. It was believed that leaving the particles saturated would have too large of an impact on the settling velocity data and yield inconclusive results. Due to this observation, the experiment evolved from a wet settling to a dry settling. A $t$-test was not conducted using the spodumene particles that were exposed to $P$. polymyxa and dried for 48 hours because this is not an economically feasible processing strategy for the lithium bearing minerals.

There were limitations to the research conducted. The settling velocity results found using Stoke's Law showed a large margin of error between the expected settling velocity of spodumene and the values obtained using the data gathered in the lab, regardless of mesh sizes. One of the assumptions when calculating with Stoke's Law is that the flow is laminar. The methods used in the lab produced a turbulent flow. This is helpful for future studies because it shows that the method of dispersal could be improved upon or a different settling chamber could be used. Finding and comparing settling velocities was the economically feasible way to prove that $P$. polymyxa would alter the surface chemistry of spodumene. There is the possibility of human error when tracking and timing the particles. To minimize that limitation all analytical methods were conducted by the same person so less variability was introduced in quantifying the settling velocities. If more funding is available for future studies the ruthenium red dye adsorption method could provide a more absolute indicator if the surface chemistry of spodumene is altered when exposed to $P$. polymyxa. Ruthenium red dye is a stock solution that binds to polysaccharides, which $P$. polymyxa is proven to generate. The adsorption density on the mineral can be analyzed to determine how effective $P$. polymyxa was in altering the surface chemistry. Another method to evaluate surficial changes on spodumene is to examine the electrokinetic properties before and after 
exposure. Electrophoretic mobilities and the isoelectric point in quartz have been found to shift towards positive values after exposure to $P$. polymyxa. In previous studies a Fourier transform infrared (FTIR) spectrophotometer was also used to observe the surficial changes in quart after exposure to $P$. polymyxa. The results showed that the vibrational bands were changed after exposure due to the absorption of polysaccharides onto the mineral surfaces. Finally, contact angles were measured to quantify the treatment's success in altering mineral surfaces. It was found that the contact angle of quartz increased with enhanced hydrophobicity (Deo and Natarajan, 1998). Despite these limitations, the methods explored in this project offer a promising new strategy to recover and recycle lithium. The settling velocity profiles show potential for the future uses of $P$. polymyxa in the recovery of lithium bearing minerals.

\section{Conclusions}

In conclusion, the findings in this experiment illustrate the potential for altering the hydrophobicity using $P$. polymyxa to recovering lithium in processing spodumene from pegmatite. In future studies, more components should be added to the experiment. Gangue material will be present in real-world scenarios of recovering and recycling lithium. The process will be more complex than the one explored in this report and requires further feasibility testing regarding whether $P$. polymyxa remains effective at altering the settling velocity profile of spodumene with the addition of other materials. At first, this could be done by selecting one mineral that is commonly present in pegmatites, such as quartz or feldspar, to create a binary mixture with the spodumene (Patra and Natarajan, 2006). Eventually, the experiment can evolve to exposing all components of the waste material to $P$. polymyxa and observing if spodumene is selectively separated from the gangue. With further development and testing of the ideas presented in this paper, $P$. polymyxa could present a sustainable method for recycling lithium, contributing to the supply of storage units used in the global transition to green energy.

\begin{tabular}{|l|r|r|r|}
\hline \multicolumn{1}{|c|}{ Mesh Size $\nabla$} & \multicolumn{1}{c|}{100} & \multicolumn{1}{c|}{200} \\
\hline W/Org. (dried-48 hrs) & 22.164 & 16.223 & 13.337 \\
\hline W/Org. (dried-24 hrs) & 15.323 & 15.675 & 12.291 \\
\hline W/Org. (24 hrs) & 22.722 & 21.308 & 21.416 \\
\hline No Org. & 16.777 & 16.206 & 12.569 \\
\hline
\end{tabular}

Table 1: Average settling velocities for spodumene based on particle size and exposure to P. polymyxa. 


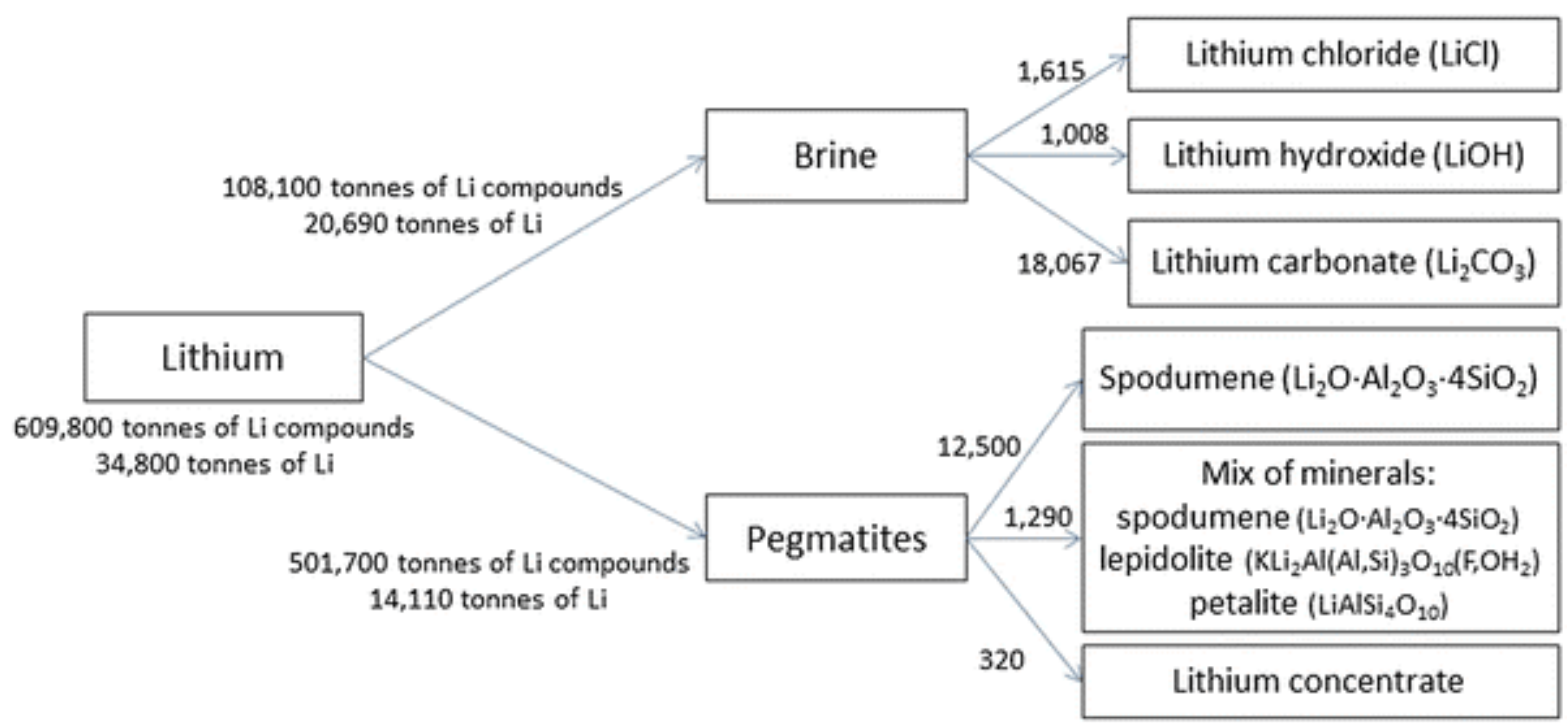

Figure 1: Main sources of lithium used for production (Peiró et al., 2013).

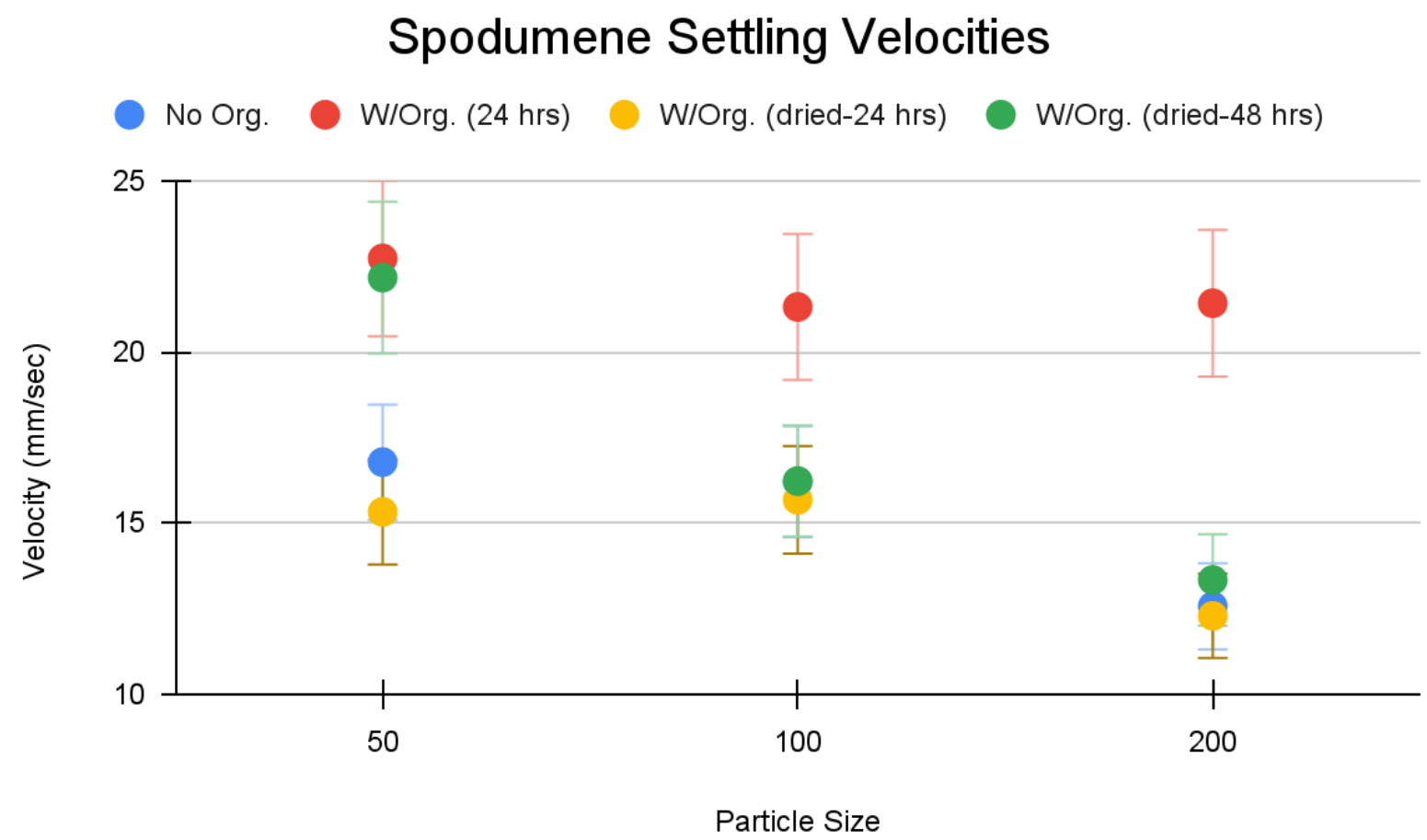

Figure 2: Settling velocities of the lithium bearing mineral spodumene with different exposures and processing treatments of the bacterium $P$. polymyxa. 


\section{Reference List}

Ambrose, H., and Kendall, A., 2019, Understanding the future of lithium: Part 2, temporally and spatially resolved life-cycle assessment modeling: Journal of Industrial Ecology, v. 24, p. 90-100, doi: 10.1111/jiec.12942.

Bowell, R.J., Lagos, L., Hoyos, C.R.D.L., and Declercq, J., 2020, Classification and Characteristics of Natural Lithium Resources: Elements, v. 16, p. 259-264, doi: 10.2138/gselements.16.4.259.

Deo, N., and Natarajan, K., 1998, Studies on interaction of Paenibacillus polymyxa with iron ore minerals in relation to beneficiation: International Journal of Mineral Processing, v. 55, p. 41-60, doi: 10.1016/s0301-7516(98)00020-9.

Evans, R.K., 1978, Lithium Reserves And Resources: Lithium Needs and Resources, v. 3, p. 379-385, doi: 10.1016/b978-0-08-022733-7.50022-8.

Graham, J.D., Rupp, J.A., and Brungard, E., 2021, Lithium in the Green Energy Transition: The Quest for Both Sustainability and Security: Sustainability, v. 13, doi: 10.3390/su132011274.

Grosjean, C., Miranda, P.H., Perrin, M., and Poggi, P., 2012, Assessment of world lithium resources and consequences of their geographic distribution on the expected development of the electric vehicle industry: Renewable and Sustainable Energy Reviews, v. 16, p. 1735-1744, doi: 10.1016/j.rser.2011.11.023.

Kavanagh, L., Keohane, J., Cabellos, G.G., Lloyd, A., and Cleary, J., 2018, Global Lithium Sources-Industrial Use and Future in the Electric Vehicle Industry: A Review: Resources, v. 7, p. 57, doi: 10.3390/resources 7030057.

Lal, S., and Tabacchioni, S., 2009, Ecology and biotechnological potential of Paenibacillus polymyxa: a minireview: Indian Journal of Microbiology, v. 49, p. 2-10, doi: 10.1007/s12088-009-0008-y.

Meshram, P., Pandey, B., and Mankhand, T., 2014, Extraction of lithium from primary and secondary sources by pre-treatment, leaching and separation: A comprehensive review: Hydrometallurgy, v. 150, p. 192-208, doi: 10.1016/j.hydromet.2014.10.012.

Munk, L.A., Hynek, S.A., Bradley, D.C., Boutt, D., Labay, K., and Jochens, H., 2016, Lithium Brines: A Global Perspective: Rare Earth and Critical Elements in Ore Deposits, doi: 10.5382/rev.18.14.

Narins, T.P., 2017, The battery business: Lithium availability and the growth of the global electric car industry: The Extractive Industries and Society, v. 4, p. 321-328, doi: 10.1016/j.exis.2017.01.013.

Nieder, R., Weber, T.K., Paulmann, I., Muwanga, A., Owor, M., Naramabuye, F.-X., Gakwerere, F., Biryabarema, M., Biester, H., and Pohl, W., 2014, The geochemical signature of raremetal pegmatites in the Central Africa Region: Soils, plants, water and stream sediments in the Gatumba tin-tantalum mining district, Rwanda: Journal of Geochemical Exploration, v. 144, p. 539-551, doi: 10.1016/j.gexplo.2014.01.025.

Okunlola, O.A., and Ocan, O., 2002, The expected environmental impact and mitigation studies of organised mining of rare metal ( $\mathrm{Ta}-\mathrm{Sn}-\mathrm{Nb}$ ) pegmatites around Keffi area, north central Nigeria: Journal of Environmental Extension, v. 3, doi: 10.4314/jext.v3i1.2690.

Patra, P., and Natarajan, K.A., 2006, Surface chemical studies on selective separation of pyrite and galena in the presence of bacterial cells and metabolic products of Paenibacillus 
polymyxa: Journal of Colloid and Interface Science, v. 298, p. 720-729, doi: 10.1016/j.jcis.2006.01.017.

Peiró, T.L., Méndez, V.G., and Ayres, R.U., 2013 Lithium: Sources, Production, Uses, and Recovery Outlook: JOM v. 65, p. 986-996, doi: 10.1007/s11837-013-0666-4.

Phalguni, A., Modak, J.M., Natarajan, K.A., 1996. Biobeneficiation of bauxite using Bacillus polymyxa: calcium and iron removal. Int. J. Miner Process. 48, 51-60.

Peters, J., and Weil, M., 2016, A Critical Assessment of the Resource Depletion Potential of Current and Future Lithium-Ion Batteries: Resources, v. 5, p. 46, doi: $10.3390 /$ resources 5040046 .

Rosendahl, K.E., and Rubiano, D.R., 2019, How Effective is Lithium Recycling as a Remedy for Resource Scarcity?: Environmental and Resource Economics, v. 74, p. 985-1010, doi: 10.1007/s10640-019-00356-5.

Sharma, P.K., and Rao, K.H., 1999, Role of a heterotrophic Paenibacillus polymyxa bacteria in the bioflotation of some sulfide minerals: Mining, Metallurgy \& Exploration, v. 16, p. 35-41, doi: $10.1007 / \mathrm{bf03403232.}$

Sonoc, A., and Jeswiet, J., 2014, A Review of Lithium Supply and Demand and a Preliminary Investigation of a Room Temperature Method to Recycle Lithium Ion Batteries to Recover Lithium and Other Materials: Procedia CIRP, v. 15, p. 289-293, doi: 10.1016/j.procir.2014.06.006.

Tost, M., Hitch, M., Chandurkar, V., Moser, P., and Feiel, S., 2018, The state of environmental sustainability considerations in mining: Journal of Cleaner Production, v. 182, p. 969977, doi: 10.1016/j.jclepro.2018.02.051.

U.S. Geological Survey, 2021, Mineral commodity summaries 2021: U.S. Geological Survey, 200 p., https://doi.org/10.3133/mcs2021.

Wanger, T.C., 2011, The Lithium future-resources, recycling, and the environment: Conservation Letters, v. 4, p. 202-206, doi: 10.1111/j.1755-263x.2011.00166.x. 